\title{
Manipulated structural variability affects the habitat choice of two ground-living beetle species in a laboratory experiment
}

\author{
Karolina Nittérus, Åsa Gunnarsson \& Bengt Gunnarsson
}

\begin{abstract}
Nittérus, K., Gunnarsson, Å. \& Gunnarsson, B. 2008: Manipulated structural variability affects the habitat choice of two ground-living beetle species in a laboratory experiment. - Entomol. Fennica 19: 122-128.

The habitat choice of two ground-living carabid beetle species (Pterostichus oblongopunctatus (Fabricius) and Carabus hortensis Linneaus) was investigated in a laboratory experiment. Beetles were released in test arenas with two options of manipulated structural variability on the ground, i.e.; bare ground spots versus spots with logging residue (slash). Beetles were studied for 600 seconds and the total time spent on bare ground versus in slash was measured. The results revealed a preference for slash covered ground amongst the investigated beetles. Regardless of species or type of release spot (in the middle of the bare ground or in slash), the carabids resided significantly longer in slash compared with the bare ground. The results support recent studies emphasizing the importance of microhabitat variability for the abundance distribution of arthropods in managed systems.

K. Nittérus \& B. Gunnarsson, Department of Plant and Environmental Sciences, Göteborg University, Box 461, SE-405 30 Göteborg, Sweden; corresponding author's e-mail: karolina.nitterus@dpes.gu.se

A. Gunnarsson, Raketgatan 3, SE-413 20 Göteborg, Sweden
\end{abstract}

Received 26 July 2006, accepted 26 October 2007

\section{Introduction}

The quality of a certain habitat is mainly determined by the large scale heterogeneity in the chosen landscape but also the variability of the structural complexity on the micro scale. Habitat complexity is regarded a key component for most arthropod communities (Thomas \& Marshall 1999, Lassau et al. 2005). Structural variability of the microhabitat functions both as a driving force for arthropod dispersal (Crist et al. 1992, Martin et al. 2001, Buddle \& Rypstra 2003) and sustains arthropod diversity (Gardner et al. 1995, Benton et al. 2003, Boulton et al. 2005).

By moving in or out of different habitat patches in a heterogeneous landscape, an organ- ism may alter its fitness (Travis \& Dytham 1999). For instance, the small scale daily movements or habitat choices of arthropods have many possible explanations such as food search and protection from predation (Harwood et al. 2001, Ferguson 2004), or balancing out environmental factors like heat or draught (Thiele 1977). Other reasons for specific distributions patterns of arthropods may be due to habitat fragmentation (Schtickzelle $\&$ Baguette 2003) or the spatial arrangement of local landscape elements (Thomas et al. 1998, Jopp \& Reuter 2005).

There are some experimental studies which have studied the relationship between arthropod habitat choice and small scale structural complexity in specific. For instance, Crist et al. 
Table 1. The biology, body size and main habitat choice of the carabid species Pterostichus oblongopunctatus and Carabus hortensis.

\begin{tabular}{|c|c|c|c|}
\hline & Biology: substrate requirements ${ }^{1}$ & $\begin{array}{l}\text { Range of body } \\
\text { size }(\mathrm{mm})^{1}\end{array}$ & $\begin{array}{l}\text { Habitat } \\
\text { choice }^{2}\end{array}$ \\
\hline P. oblongopunctatus & $\begin{array}{l}\text { in forest litter, moss or under pebbles } \\
\text { or tree stumps, on moist ground } \\
\text { in mixed- or deciduous forest }\end{array}$ & $9.5-12.6$ & Forest \\
\hline C. hortensis & $\begin{array}{l}\text { mixed forest with thick humus layers, } \\
\text { partly shaded patches, preferably } \\
\text { sandy ground }\end{array}$ & $22-28$ & Forest \\
\hline
\end{tabular}

1 according to (Lindroth 1985, 1986).

2 according to $\mathrm{H}$. Ljungberg, pers. comm.

(1992), Johnson et al. (1992) and McIntyre and Wiens, (1999) showed that the moving behaviour of Tenebrionid beetles (Elodes spp.) was mainly regulated by various habitat characteristics. Kindvall et al. (2000) found comparable strong interactions between substrate variability and the moving behaviour of Pine weevils (Hylobius abietis).

In Gunnarsson et al. (2004), we showed that certain forestry activities i.e., harvest of slash (logging residues from clear-cuttings) for biofuel in commercial mixed and coniferous forests, caused changes of the ground layer complexity, with important effects on ground-beetle populations. We found a significant positive relationship between microhabitat complexity (i.e. aboveground height of slash heaps) and beetle abundance. Moreover, species richness of morpho species (i.e., beetle specimens were separated into recognizable taxonomic units (RTUs) for estimates of species richness according to Oliver \& Beattie 1993, 1996) was significantly lower in sites were slash was removed than in sites where slash was left on the ground (Gunnarsson et al. 2004). Furthermore, in a follow-up experiment, we investigated how carabids reacted to manipulations of the microhabitat complexity on the ground of clear-cuts. We collected significantly more carabid individuals in the high complexity patches (slash covered spots) than in the low complexity patches (bare ground spots) in the field experiment and also we found a significant positive correlation between the number of carabids and the aboveground height of slash, in non-manipulated, reference plots (Nittérus \& Gunnarsson 2006).
The aim of the present study is to explore the mechanisms for carabid habitat choice, on the micro scale under more controlled circumstances. The study is therefore carried out in two test arenas in the laboratory by using field-collected beetles. Carabid beetles (Coleoptera: Carabidae) were chosen as study objects, since carabids in general are common, widespread, and inhabit or hunt for prey on the ground of most forested ecosystems (Thiele 1977, Larsen et al. 2003). The two selected species Pterostichus oblongopunctatus (Fabricius) and Carabus hortensis Linneaus are typical forest species, frequent in clear-cuts all over Sweden and both species have been collected in our previous studies. The main study hypothesis is that the two carabid species will spend more time in high complexity patches (slash covered spots) than in the low complexity patches (bare ground spots) as found in our previous experiments in the field.

\section{Material and methods}

\subsection{Sampling of carabids and organic material}

In September 2002, 26 living specimens of the two chosen carabid species, i.e., Pterostichus oblongopunctatus and Carabus hortensis (for further information on their biology see Table 1.) were collected by use of pitfall traps on a 1-year old clear-cut. The clear-cut was located in southern Sweden, approx. 57 $50^{\prime} \mathrm{N}, 12^{\circ} 9^{\prime} \mathrm{E}$. Pitfall traps were emptied every third day and no preservatives were used. 
All living specimens of the two selected species were brought back to the laboratory and kept, solitary in moisturized containers, in the refrigerator $\left(+8^{\circ} \mathrm{C}\right)$ for approximately 15 days. To synchronize the feeding state of the collected beetles, no feeding was carried out during the entire experiment (from collection in the field to the end of the experiment). Fourteen hours before experimental start-up, the beetles were removed from the refrigerator for acclimatization in room temperature. To synchronize the day-rhythm of beetles prior to the experiment, each specimen was illuminated with an 11-Watts fluorescent tube during the first twelve hours, to simulate day-light and reduce night-active behaviour (Thiele 1977, Lindroth 1985, 1986). However, the last two hours prior to the experiment, the fluorescent tube was shut off to stimulate their night-active behaviour.

The organic material, i.e. layers of moss (Hypnum cupressiforme) and logging residue (slash) covering the bottom of the two test arenas (described below), was gathered on the ground of the same clear-cut as above a couple of weeks prior to the experiment. To defaunate the moss layer and slash from possible preys prior to the experiment, the material was first dehydrated for 3 weeks indoors (in room temperature) and searched through by hand, before being placed in the test arenas.

\subsection{Test arenas}

Two circular shaped test arenas were constructed, made out of corrugated 2-mm isolation-plastic consisting of a bottom joined together with an enclosure-barrier (Fig. 1). The diameter of each arena was $0.8 \mathrm{~m}$ and the barrier height was 0.12 m.

The organic material within the arenas was arranged in two separate ways (Fig.1); either with an elongated bare ground spot in the middle surrounded by slash (arena A), or with an elongated slash covered spot in the middle surrounded by bare ground (arena B). The bare layers of moss ( $\sim 3 \mathrm{~cm}$ thick) without any slash cover simulated "bare ground" while the $\sim 8 \mathrm{~cm}$ high spots of slash on top of the $\sim 3 \mathrm{~cm}$ thick layers of moss simulated "slash covered ground". Both types of "ar-

\section{Test arenas}

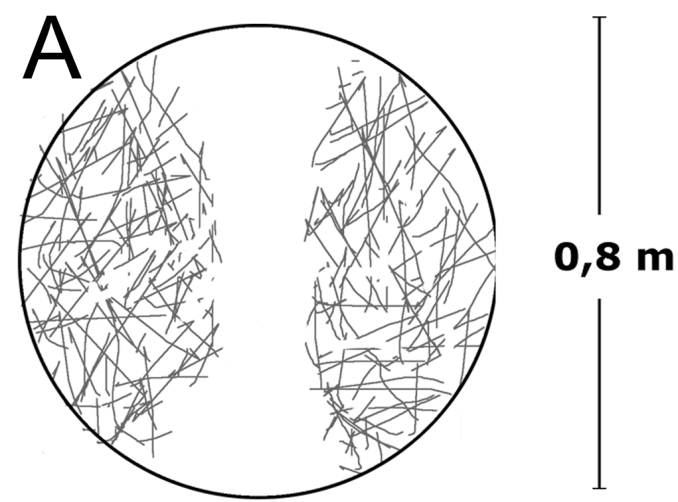

\section{bare ground middle}

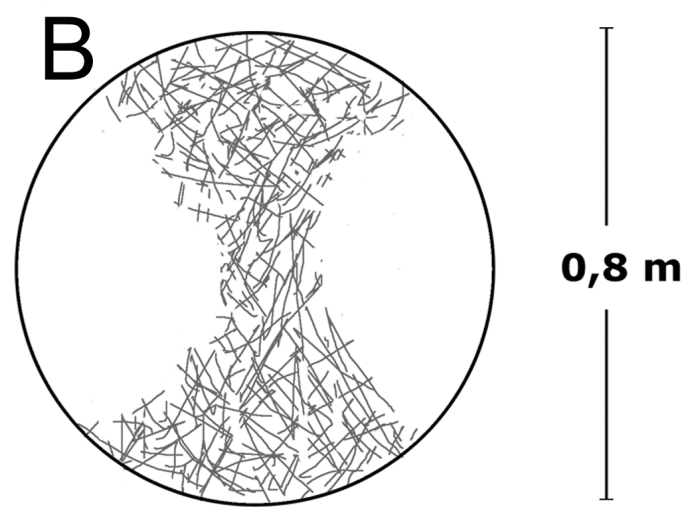

\section{slash covered middle}

Fig. 1. The two experimental test arenas. Test arena A has bare ground middle and slash covered surroundings, whereas test arena B has slash covered middle and bare ground surroundings.

rangements" included equal areas of bare and slash covered ground as well as equal amounts of slash and moss on the bottom of the arenas. The somewhat complex shape of the bare vs. slash covered spots was made to ensure that the plastic edge around the arena was in contact with both habitats in an equal way and did not affect the outcome. Consequently, although this arrangement appeared rather complex, it simplified the experiment by enabling a more straightforward inter- 
pretation of the results. Other types of slash arrangements would also have been possible, but were not tested in the present study.

\subsection{The experiment}

The entire experiment was conducted in darkness to simulate night conditions and to evoke nightactive behaviour (Thiele 1977, Lindroth 1985, 1986). However, since beetles probably cannot apprehend red light (Mentzel 1979), a red dark room light was used during parts of the experiment, to enable visual tracking of the beetles. Furthermore, to enhance visualisation of the smaller specimens, a minor white marking was made on their elytra, by use of a drop of white correcting fluid, from a correcting pen.

All beetles were placed in the middle of both arenas and were consequently used twice. A specimen was first put in test arena A (with bare ground middle) and then in B (with slash covered middle) or vice versa. The order, of which test arena was first used, was randomized for each specimen. After a test in the first arena, the specimen was instantly removed to rest for $\sim 1$ hour, before being used again. For each specimen, timing continued for 600 seconds in total and started when the beetle specimen started to move, in any direction. Total time spent in slash versus total time spent on the bare ground out of the $600 \mathrm{sec}-$ onds was the only factor recorded. No further details on the individual's particular dispersal patterns or moving behaviours were observed or recorded since the present study is focused on the beetle's habitat choice in a setting composed of only two different options (i.e., high complexity/slash covered vs. low complexity/bare ground).

\subsection{Statistics and analyses}

The dataset was small and not normally distributed. Due to related samples (the time spent on bare ground versus in slash) non-parametric Wilcoxon signed ranks tests were used. In the analyses, median time spent in slash, split by species and release spot were used. Furthermore, Spearman rank order correlations were assessed
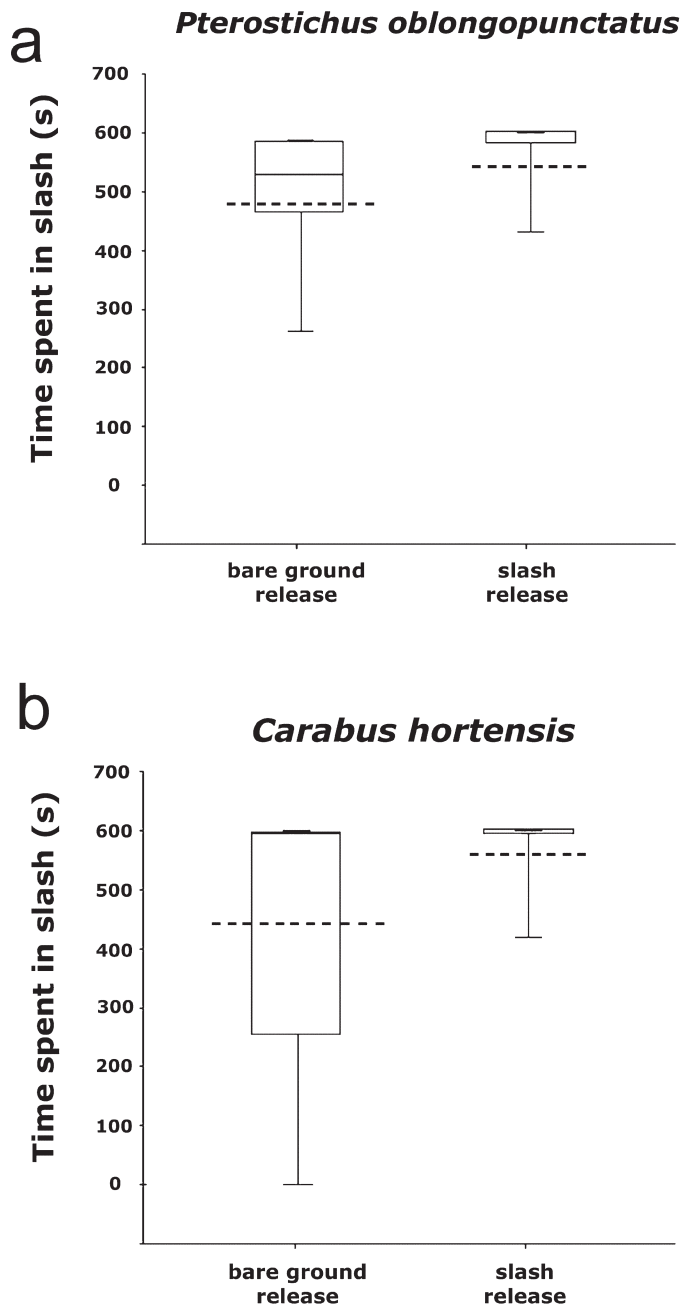

Fig. 2. The time and spent in slash (out of $600 \mathrm{sec}-$ onds) when released in the middle of the two test arenas. - a. Pterostichus oblongopunctatus. - b. Carabus hortensis. Percentiles (10, 25, 50, 75 and 90) are included in each bar. The dashed line denotes mean time spent.

for associations between carabid body weight and time spent in slash. All analyses were carried out by use of the software package "SPSS for Windows, version 13.0” (SPSS Inc. 1989-2004).

\section{Results}

The time spent in slash for specimens of $P$. oblongopunctatus, released on bare ground (arena A), were significantly higher than the time spent on bare ground (Wilcoxon signed ranks 
Table 2. The time spent in slash (out of 600 seconds) by the selected carabid species after release in two test arenas (bare ground vs. slash covered). Table shows mean and standard deviation, minimum, maximum values and percentiles for each category.

\begin{tabular}{llllll}
\hline & Release spot & $N$ & Mean (S.D.) & Min./Max. & $\begin{array}{l}\text { Percentiles: } \\
\text { Median }\left(25^{\text {th }} / 75^{\text {th }}\right)\end{array}$ \\
\hline P. oblongopunctatus & Bare ground & 12 & $481(166)$ & $0 / 589$ & $528(451 / 584)$ \\
& Slash covered & 12 & $543(172)$ & $0 / 600$ & $600(578 / 600)$ \\
C. hortensis & Bare ground & 13 & $432(256)$ & $0 / 598$ & $592(168 / 595)$ \\
& Slash covered & 13 & $562(95)$ & $275 / 600$ & $600(588 / 600)$ \\
\hline
\end{tabular}

test, $p=0.034)$ (Fig. 2 and Table 2.). And once again, when released in slash (arena B), $P$. oblongopunctatus specimens spent significantly more time in slash than on the bare ground $(p=$ 0.008) (Fig. 2 and Table 2.).

However, for $C$. hortensis specimens, released on bare ground (arena A), no significant difference $(p=0.51)$ were found, between time spent in slash compared to bare ground (Fig. 2 and Table 2.). Still, when released in slash (arena B), C. hortensis specimens spent significantly more time in slash than on bare ground $(p=$ 0.001) (Fig. 2 and Table 2.).

Spearman rank order correlations, showed no significant relationships between carabid body weight and time spent in slash, neither for $P$. oblongopunctatus $(0.191<p<0.646)$, nor for C. hortensis $(0.750<p<0.923)$.

\section{Discussion}

The results of the present study support earlier results showing that arthropods respond and react towards microhabitat complexity on the micro scale (Thomas \& Marshall 1999, Traugott 2002, Gunnarsson et al. 2004, Juen \& Traugott 2004) and moreover that arthropods sometimes even actively select a certain habitat patch on the ground (Grez et al. 2005, Toews et al. 2005), or may adapt specific moving behaviours or patterns in diverse habitats (Johnson et al. 1992, Jopp \& Reuter 2005).

There are several possible mechanisms for associations between abundance, distribution or activity of arthropods and habitat complexity, for instance different interactions, such as predation pressure, between individuals (Buddle et al.
2003). Consequently, a possible reason for the non-significant result of $C$. hortensis when released on bare ground (arena A), in the present study, might be due to its importance as a predator (or as a successful competitor) for resources. Possibly, $C$. hortensis does not perceive bare ground as risky and stays searching for prey here, rather than searching for shelter from predators.

Another theory for a specific moving behaviour or habitat choice of some arthropods might be due to their specific body structure (e.g. size and length of extremities), which could affect their locomotive ability or dispersal patterns in or out of complex habitat structures (Farji-Brener et al. 2004). Consequently, one reasonable explanation to our results would be that $P$. oblongopunctatus (which is the smaller species of the two), would move slower and hereby stay longer in slash piles than on the open ground compared to $C$. hortensis. However, in the present study, we analysed for this and found no associations between body size and time spent in slash.

In a german study, carabid beetles were used to study effects of forest regeneration with selective and small scale clear-cutting on the ground and the results showed that small openings, created after clear-cuttings, probably served as an important retreat for open habitat species and that forest species were preserved during the early phase of the forest regeneration process (Huber \& Baumgarten 2005). In the present study we studied two forest species with similar habitat preferences but there is a possibility that the habitat preference needs further examination. Possibly, extreme conditions of the structural complexity can trigger or enhance, an organisms' preference for a certain habitat. This could explain why we found a difference in behaviour between the two 
species in our study although they are both regarded as forest species. It has been suggested that carabids can still be restricted to rather specific microhabitat patches in the field (Greenslade 1964).

Gunnarsson et al. (2004) and Åström et al. (2005) earlier showed that removal of logging residue from clear-cuts significantly affected the distribution of arthropods and bryophytes and vascular plants in boreal forests.

Our present results imply that slash on the ground also affects the actual habitat choice (e.g. behaviour) of some beetle species but future studies will have to explore whether the effects described here are due to changes of the microhabitat or due to other prevailing factors and whether the results also hold for other species and groups of arthropods. In particular, studies on possible mechanisms driving the dispersal of arthropods on the micro scale including the specific distribution patterns, in various habitats should be emphasized in the future.

Acknowledgements. We wish to thank P. Wirdenäs for assistance in the field and in the laboratory and M. Åström, N. Franc, E. Broman, N. Hansson and an anonymous referee for valuable comments on the manuscript. The municipal Forestry Department in Göteborg supplied us with a suitable sampling area. Financial support was received from The Swedish Energy Agency, Helge Ax:son-Johnsons Stiftelse, Wilhelm \& Martina Lundgrens Vetenskapsfond, Adlerbertska forskningsstiftelsen, Kungliga Vetenskapsakademien and Axel Phersson-Bramstorps stipendiefond.

\section{References}

Åström, M., Dynesius, M., Hylander, K. \& Nilsson, C. 2005: Effects of slash harvest on bryophytes and vascular plants in southern boreal forest clear-cuts. - J. Appl. Ecol. 42: 1194-1202.

Benton, T. G., Vickery, J. A. \& Wilson, J. D. 2003: Farmland biodiversity: is habitat heterogeneity the key? Trends Ecol. Evolut. 18: 182-188.

Boulton, A. M., Davies, K. F. \& Ward, P. S. 2005: Species richness, abundance, and composition of grounddwelling ants in northern California grasslands: Role of plants, soil, and grazing. - Environ. Entomol. 34: 96-104.

Buddle, C. M., Walker, S. E. \& Rypstra, A. L. 2003: Cannibalism and density-dependent mortality in the wolf spider Pardosa milvina (Araneae : Lycosidae). — Can. J. Zool. 81: 1293-1297.
Buddle, C. N. \& Rypstra, A. L. 2003: Factors initiating emigration of two wolf spider species (Araneae : Lycosidae) in an agroecosystem. - Environ. Entomol. 32: 88-95.

Crist, T. O., Guertin, D. S., Wiens, J. A. \& Milne, B. T. 1992: Animal Movement in Heterogeneous Landscapes: An Experiment with Eleodes Beetles in Shortgrass Prairie. - Funct. Ecol. 6: 536-544.

Farji-Brener, A. G., Barrantes, G. \& Ruggiero, A. 2004: Environmental rugosity, body size and access to food: a test of the size-grain hypothesis in tropical litter ants. - Oikos 104: 165-171.

Ferguson, S. H. 2004: Influence of edge on predator-prey distribution and abundance. - Acta. Oecol. 25: 111117.

Gardner, S. M., Cabido, M. R., Valladares, G. R. \& Diaz, S. 1995: The Influence of Habitat Structure on Arthropod Diversity in Argentine Semiarid Chaco Forest. J. Veg. Sci. 6: 349-356.

Greenslade, P. J. M. 1964: Pitfall Trapping as a Method for Studying Populations of Carabidae (Coleoptera). - J. Anim. Ecol. 33: 301-310.

Grez, A. A., Zaviezo, T. \& Rios, M. 2005: Ladybird (Coleoptera : Coccinellidae) dispersal in experimental fragmented alfalfa landscapes. - Eur. J. Entomol. 102: 209-216.

Gunnarsson, B., Nittérus, K. \& Wirdenäs, P. 2004: Effects of logging residue removal on ground-active beetles in temperate forests. - Forest Ecol. Manag. 201: 229 239.

Harwood, J. D., Sunderland, K. D. \& Symondson, W. O. C. 2001: Living where the food is: web location by linyphiid spiders in relation to prey availability in winter wheat. - J. Appl. Ecol. 38: 88-99.

Huber, C. \& Baumgarten, M. 2005: Early effects of forest regeneration with selective and small scale clear-cutting on ground beetles (Coleoptera, Carabidae) in a Norway spruce stand in Southern Bavaria (Hoglwald). - Biodivers. Conserv. 14: 1989-2007.

Johnson, A. R., Milne, B. T. \& Wiens, J. A. 1992: Diffusion in Fractcal Landscapes: Simulations and Experimental Studies of Tenebrionid Beetle Movements. Ecology 73: 1968-1983.

Jopp, F. \& Reuter, H. 2005: Dispersal of carabid beetlesemergence of distribution patterns. - Ecol. Model. 186: 389-405

Juen, A. \& Traugott, M. 2004: Spatial distribution of epigaeic predators in a small field in relation to season and surrounding crops. - Agricult. Ecosys. Environ. 103: 613-620.

Kindvall, O., Nordlander, G. \& Nordenhem, H. 2000: Movement behaviour of the pine weevil Hylobius abietis in relation to soil type: an arena experiment. - Entomol. Exp. Appl. 95: 53-61.

Larsen, K. J., Work, T. T. \& Purrington, F. F. 2003: Habitat use patterns by ground beetles (Coleoptera:Carabidae) of northeastern Iowa. - Pedobiologia 47: 205-299.

Lassau, S. A., Cassis, G., Flemons, P. K. J., Wilkie, L. \& Hochuli, D. F. 2005: Using high-resolution multispectral imagery to estimate habitat complexity in 
open-canopy forests: can we predict ant community patterns? - Ecography 28: 495-504.

Lindroth, C. H. 1985, 1986: Fauna Entomologica Scandinavia: The Carabidae (Coleoptera) of Fennoscandia and Denmark. Part $1 \&$ 2. - Scandinavia Science Press Ltd., Copenhagen. 497 pp.

Martin, M., Bastardie, F., Richard, D. \& Burel, F. 2001: Studying boundary effects on animal movement in heterogeneous landscapes: the case of Abax ater (Coleoptera:Carabidae) in hedgerow network landscapes. - C. R. Acad. Sci. III-Vie 324: 1029-1035.

McIntyre, N. E. \& Wiens, J. A. 1999: How Does Habitat Patch Size Affect Animal Movement? An Experiment with Darkling Beetles. - Ecology 80: 2261-2270.

Mentzel, R. 1979: Spectral sensitivity and colour vision in invertebrates. - In: Autrum, H. (ed.), Handbook of Sensory Physiology: 503-580. Springer-Verlag, Berlin.

Nittérus, K. \& Gunnarsson, B. 2006: Effect of Microhabitat Complexity on the Local Distribution of Arthropods in Clear-Cuts. - Environ. Entomol. 35: 13241333.

Oliver, I. \& Beattie, A. J. 1993: A Possible Method for the Rapid Assessment of Biodiversity. - Conserv. Biol. 7: 562-568.

Oliver, I. \& Beattie, A. J. 1996: Invertebrate morphospecies as surrogates for species: A case study. - Conserv. Biol. 10: 99-109.
Schtickzelle, N. \& Baguette, M. 2003: Behavioural responses to habitat patch boundaries restrict dispersal and generate emigration-patch area relationships in fragmented landscapes. - J. Anim. Ecol. 72: 533545.

SPSS for Windows 13.0 (1 Sep 2004). 13.0. 1989-2004: SPSS Inc.

Thiele, H.-U. 1977: Carabid Beetles in Their Environments. - Springer-Verlag, Berlin. 369 pp.

Thomas, C. F. G. \& Marshall, E. J. P. 1999: Arthropod abundance and diversity in differently vegetated margins of arable fields. - Agricult. Ecosys. Environ. 72: 131-144.

Thomas, C. F. G., Parkinson, L. \& Marshall, E. J. P. 1998 : Isolating the components of activity-density for the carabid beetle Pterostichus melanarius in farmland. Oecologia 116: 103-112.

Toews, M. D., Arthur, F. H. \& Campbell, J. F. 2005: Role of food and structural complexity on capture of Tribolium castaneum (Herbst) (Coleoptera : Tenebrionidae) in simulated warehouses. - Environ. Entomol. 34: 164-169.

Traugott, M. 2002: Dispersal power, home range and habitat preference of cantharid larvae (Coleoptera : Cantharidae) in arable land. — Eur. J. Soil Biol. 38: 79-83.

Travis, J. M. J. \& Dytham, C. 1999: Habitat persistence, habitat availability and the evolution of dispersal. Proc. R. Soc. Lond. [Biol] 266: 723-728. 